\title{
An Integrative Approach in Treating Complete Food Refusal in Children: a Case Study
}

\author{
Khamsiah Ismail, Ph. D \\ Kulliyyah of Education, International Islamic University Malaysia \\ Assistant Professor \\ ikhamsiah@iium.edu.my \\ Siti Rafiah Abd Hamid, Ph. D \\ Kulliyyah of Education, International Islamic University Malaysia \\ Assistant Professor \\ srafiah60@iium. edu.my
}

\begin{abstract}
Eating disorders among children may be attributed to the range of complications associated with feeding problems; from mild (e. g. , missed meals) to total food rejection. Many early feeding problems can be diagnosed and corrected either by medical interventions, therapies or behavioural modification. Parents might use reward system in persuading them to eat and in extreme cases, pressure, force and punishment are also applied. There are also cases of children who do not eat at all and simply refuse to eat. For parents of children with feeding disorders, this is the beginning of a long and challenging journey that will include many medical and clinical experts. This paper presents the case study of a 13-year old boy with borderline autism, dyslexia and $A D H D$ who did not consume any food at all i. e. complete food refusal for the first 12 and a half years of his life. In his treatment strategies, the therapist utilized a combination of several interventions strategies based on a few theoretical approaches. This integrative approach designed for his treatment intervention was divided into four phases comprising of: (i) Person-Centred; (ii) Behavioural Therapy; (iii) Cognitive Behavioural Therapy; and (iv) Psycho-educational. His family was also involved in the treatment. This study found that the approaches used in the treatment helps to improve the boy's eating problem as he started to eat pureed and soft food such as porridge. The therapy has also helped him gained self-confidence and improved his communication as well as social skills. He was healthier as he had not been admitted to hospital after the therapy ended. The findings of this study provide evidence that eating disorder problem involving children can be treated with psychotherapy. The treatment plan can be utilized to initiate suitable intervention as an effort to help children as well as adolescents manages their eating problems.
\end{abstract}

Keywords: Eating disorder, total food rejection, integrative approach, Person-Centred approach, Behavioural Therapy, Cognitive Behavioural Therapy, Psycho-Educational Approach

\section{Introduction}

For many parents, baby's first bite of food is a delightful moment as this is the move leading to a lifetime of memorable family experience of happy mealtimes. Unfortunately, while many parents strive to integrate fruits and vegetables into their child's diet once they start to take solid food, there are children who simply reject the food selections made for them. Parents may plead, persuade or use non-food reward to their children to try new foods. In extreme cases, pressure, force and punishment are also applied. Nonetheless, with some children, none seems to work. For parents of children with feeding delays and disorders, this is the beginning of a long and challenging journey that will include many medical and clinical experts such as gastrointestinal specialists, paediatricians, nutritionists, dieticians and psychologist. 
Many early feeding problems can be diagnosed and corrected either by medical interventions, therapies or behavioural modification. Over a period of time, with appropriate interventions and parental efforts, young children who cannot eat properly due to a developmental or physical impairment can gradually improve and begin to consume solid food. But what about children who refuse to eat? This is different for a child who cannot eat for a definable reason or diagnosable problem. In many instances, parents trying everything under the sun to get their children to eat but to no avail. However, there are cases of children who do not eat at all and simply refuse to eat. For the parents of these children, the journey of making their children eat can be painful.

This paper presents the case study of a 13-year old boy who did not accept any food at all i. e. complete food refusal for the first 12 and a half years of his life. An integrative approach was designed for his treatment intervention.

\section{Client's Information}

Arief (was given a pseudonym to maintain the ethic of confidentiality) was a 13 year-old boy of Malay ethnic. He was the eldest child of two siblings and his brother was four years younger than him. He attended a class for special educational need student at an integrated primary school. Based on early observation ie. when he was brought to the therapist, Arief was able to do basic arithmetic (simple addition and subtraction) but quite slow in his reading. His language ability and communication was considerably good.

Arief lived with his parents and at weekdays they stayed with his maternal grandparents as his mother helped them to run food catering business and manage a restaurant which was located near their house. The school that he attended was not far from his grandparent's house and hence his family only returned home at weekends. His father worked at the information technology department in a commercial bank. The family had no problem in getting good and healthy food for him but their main concern was that he just refused to eat and totally refused to consume any solid food.

\section{Presenting the Problem}

Arief was nine years old when he was referred for treatment in 2009. He seemed not to be interested in food and had never eaten - neither solid nor pureed food at all since his infancy. However, he has no problem swallowing water. Arief would only drink especially milk and most of the time using feeding bottle. As he has normal height for his age although fairly thin, he seemed to get enough nutrients from the milk that he drank. He seemed not to have any emotional problems. Arief had been referred to paediatricians. Other than asthmatic and gastric, medical assessments indicated that there were no physical and health problems that would explain his symptoms. He had been admitted to hospital several times due to his asthmatic and gastric-related problems. His parents also reported that he got tired easily.

They had tried to give him food but to no avail. Arief told them that he did not feel hungry. His parents had been worried about his complete refusal of food as any attempts to help him to eat were met with resistance. They felt that all investigations had been conducted at various hospitals but there was no definite diagnosis made about his problem. They also reported that based on doctors' observation and prior medical reports, the child was said to have borderline autism, dyslexia and attention deficit hyperactivity disorder (ADHD).

Arief's parents claimed that he could not be fed with solid foods since infancy. He was breastfed for three months and then was given formula feeding. He only tolerated milk and nutritious fluids as soya, ribena, vitagen and pedisure milk. He also liked orange juice but it caused him to have gastric pain. He refused to take solid food such as nestum or porriage but he liked to lick soya sauce which was salty. Intermittently, he had abdominal pain that required hospital admission.

Arief did not show oral motor delays. However, his mother observed that Arief had low self-esteem at school. This was probably due to his diet problems as he was still dependent on bottle feeding. Apart from having borderline autism, dyslexia and ADHD, one of the reasons that the parents had to enrol him in a special class was Arief needed help from teachers to make milk for him and special educational need class was quite flexible with their students' routines. Teachers and their assistant were always around and provided helps to the students with special needs and attended to their physical needs. 


\section{Client's History Client's History}

Arief could not tell the therapist about his eating problem. He simply said "I don't know"; "I don't want to eat"; and "I don't like to eat". Hence, information from the parents enabled the researcher to procure some ideas about the possible causes of his problem. Series of interview were conducted on Arief's parents. Information obtained from them is briefly presented in this section.

Base on his medical reports brought by the parents in the first therapy session, Arief was born preterm at 32 weeks via lower segment caesarean section (LSCS) and his birth weight was 2. 42 kilogram. At postnatal, he had distressed syndrome and required assisted ventilation for 10 days in neonatal intensive care unit (NICU). He walked at the age of 13 months. According to the parents, his facial appearance was normal, like other normal children. The first six months of Arief's life were that of a normal baby. Arief's nutrition was his mother's breast and formula milk. He was sent to a baby sitter after his mother's maternity leave ended. At the age of about six or seven months old Arief was hospitalized due to bronchitis and phlegm suction procedure was conducted on him in which, suction tube was put through his throat. His father recalled that the procedure was done for at least three consecutive days. To avoid him from struggling, Arief was wrapped with hospital blanket.

After he was discharged from hospital, Arief's parents said that they had difficulty in feeding him as he started to reject milk and baby food that were given to him but after much persuasion and force, he only consumed milk from feeding bottle and prior to coming for therapy, he drank six to eight bottles of formula milk per day. He was still a bottle dependent and would not drink from other container such as glass and normal bottle. This meant that he had not taken any solid food until the age of 12 . The parents reported that there was no family history of similar problem.

Arief's total rejection of food had also affected his relationships with his friends. He could not play football and other games with his friends as he got tired easily and there were several occasions that he had almost fainted. Apart from that, he could easily get asthma attack.

The following sections present a brief literature review related to eating disorders and total food rejection among children. It is followed by presentation of counselling and psychological approaches applied in the therapy which comprises of the treatment strategies and interventions in helping Arief to eat.

\section{Review of Literature}

Eating is a complex reaction consisting of a chain of behaviours that include accepting, chewing, and swallowing the food or drink (Bachmeyer, 2010). When a bite of food enters a child's mouth, the child can allow the bite by the teeth, further inside the mouth on the mid-tongue, with mouth closure, and later allowing the food to be swallowed. However, feeding can be challenging to some children and it is relatively common among typically developing children, with reported prevalence rates of up to $29 \%$ (Bachmeyer, 2010). Feeding problems may be attributed to the range of complications associated with feeding problems, from mild (e. g. , missed meals) to total food rejection.

Children with the most significant feeding problems are often described as having food refusal. Food refusal has been defined as a general term that embraces a wide range of a child's feeding problems (Chatoor \& Ganiban, 2003; Douglas, 2002, cited in Gardner \& Shaw, 2008). Specifically, it refers to a child's refusal to eat all or most foods presented, resulting in the child's failure to meet his or her caloric and nutritional needs (Field, Garland, \& Williams, 2003). Decreased appetite can also be applied to food refusal (Stainano, 2003). Unpredictable food refusal, selective food refusal and fear-based food refusal are among the expressions of food refusal (Chatoor \& Ganiban, 2003) and resulting in dependence on liquid oral feedings (e. g. , bottle feeding, tube feeding).

Total or complete food refusal however has not been directly mentioned in The Diagnostic and Statistical Manual of Mental Disorders - Text Revision (DSM-IV-TR) (APA, 2000). Nevertheless feeding disorder of infancy or early childhood in DSMIV-TR has been renamed in version of the DSM-5 as avoidant/restrictive food intake disorder (APA, 2013). The criteria for this disorder also have been significantly expanded to include individuals, primarily but not exclusively children and adolescents, substantially restrict their food intake and experience significant associated physiological or psychosocial problems but do not meet criteria for any DSM-IV eating disorder. Avoidant/restrictive food intake disorder is a broad category intended to capture this range of presentations (Grohol, 2013). "Some authors have conceptualized eating 
disorders in pre-pubertal children as early manifestations of anorexia nervosa, but these children rarely met DSM-III-R diagnostic criteria" (Singer, Ambuel, Wade and Jaffe, 1992, pp 847, cited in Vaughan, 2000). Nevertheless, their health risks can be are just as serious as those risks for children with a clear diagnosis.

Studies have reported that the prevalence of eating problems in general was found to be high among children with developmental disabilities, with rates ranging from as high as 35\% (Bachmeyer, 2009). Findings from the studies revealed that, children who have been identified by the refusal of food have also been diagnosed with a developmental disability.

Although food refusal is relatively common, it can pose a significant health risk for some children (Chatoor \& Ganiban, 2003). Children who refuse food have similar health risks to people diagnosed with anorexia and food deficiency, for any grounds, can cause physical problems. Severe food refusal, if left untreated, can result in weight loss, malnutrition, fatigue, impaired mental or physical development, and even death (Christophersen \& Hall, 1978 as cited in Bachmeyer, 2010). It can also cause more serious effect on the psychological development of children. Their eating disorder can also lead to persistent medical procedures, admission to hospital, and eventually cause limitation in social emotional as well as educational functioning and development (Kerwin, 1999). Thus, early intervention and treatment of eating disorders such as food refusal is extremely important in caring for the health of the children as well as the adolescents.

Limited literature was found about eating disorders in pre-pubertal children, especially those who are otherwise healthy and have no obvious developmental disabilities (Singer et. al. , 1992, in Vaughan, 2000). Most of the researchers focus on other types of eating disorders affecting children and teen agers such as bulimia, anorexia nervosa and binge eating. There are also numerous literatures on children eating problem such as neophobia, selective eating, picky eating, restrictive eating and binge eating especially among children. Treatment for total food rejection is even more critical. Many intervention strategies and theoretical approaches were suggested and utilised but little has been written on treatment of total food rejection. Among the treatments presently offered to treat a range of eating disorders include antidepressant medication, hospitalization, individual psychotherapy, family therapy, classical and operant conditioning, and cognitive restructuring (Vaughan, 2000). In relation to individual psychotherapy, behaviour analysis was recommended as one the effective preliminary approach to identify problematic behaviours during mealtimes and then to "teach" an appropriate set of behaviours that will yield a proper mealtime experience (Zimmerman, 2010). Others suggested Cognitive-behavioural Therapy (CBT) for the treatment of eating disorders (Hay, Bacaltchuk, Stefano \& Kashyap, 2009) as they believed that the approach has been effectively utilized in many treatment procedures (Murphy, Straebler, $\underline{\text { Cooper }}$ \& Fairburn, 2010).

Identifying and diagnosing eating problems in children can be more challenging than we might think. However, upon obtaining and analyzing the information from the parents as well as literatures on eating disorder-related studies, it is believed that this 13-year old boy's total food rejection was due to fear and traumatic experience. This assumption is also based on one of Chator and Ganiban's (2003) postulation that an expression of food refusal can also be observed in different qualitative ways including fear-based food refusal. In this case study, the therapist explored the utilization of a combination of several interventions strategies based on a few theoretical approaches i. e. an integrative approach in treating a young client who totally rejected food since infancy.

\section{Treatment Intervention Plan}

It is important to note that the intervention was planned to treat Arief eating-related problem. The therapist did not conduct any assessment for his reported borderline autism, dyslexia and ADHD as the problem has been diagnosed by medical doctors earlier. For his complete food rejections problem, intervention plan for Arief's treatment was divided into four phases as follows:
i. Person-Centred approach
ii. Behavioural Therapy
iii. Cognitive Behavioural Therapy
iv. Psycho-Educational Approach 


\section{Phase 1}

\section{Person-Centred Approach (PCT)}

The client was nine years old when he was first referred to the therapist. Even though his autism, dyslexia and ADHD were at borderline, it was quite challenging to get his attention. Hence, development of therapeutic relationship with this client is very important. Rogers (1957, reproduced in Kirschenbaum \& Henderson, 1990) believed that a therapist must demonstrate three core conditions which are empathetic, communicate an unconditional positive regard for the client, and shows genuineness or congruence in order to foster a strong therapeutic relationship and create a psychological atmosphere. These conditions will help the client feel safe to examine their situations and not being judged and eventually they can be empowered to take the steps necessary to grow and self-actualize (Rodriguez, n. d.). Apart from that, children and psychotherapists need to create an entire therapeutic world in which children actively engage in appropriate expression of emotion and are able to focus on their strengths (Landreth \& Bratton (2000).

\section{Intervention Strategies}

i. Development of rapport started with play therapy. It was conducted using some small toys including army and army vehicles (his own choice as he said he liked them) as well as other animal miniatures. The therapist sat on the floor with him and started talking to him but he did not respond much in the conversation. Most of the time he shook or nodded his head (indication 'yes' or 'no'), raised his shoulder or simply said "I don't know". As the therapist proceed with the play Arief felt more comfortable. He started to interact with her to share about what he liked and disliked, his family, school, and friends. There was a minimal eye contact though. Nevertheless, he did not feel safe as he also kept going to the window or door checking if the mother was still around.

ii. The next course of action was taking Arief to cafeteria and shop which were located within the therapist's office premise. This 'tour' was aimed to observe if he recognized different types of food, their names and whether he could stand the smell of the food. He could name the foods but could not take their smells. When asked to guess the taste of the food, his response was "delicious but I don't want to eat" (sedap tapi Arief tak nak makan). In the shop, he was asked to pick any food that he wanted but only took some food for his younger brother and none for him with the same remarks "I don't want to eat" (Arief tak nak makan).

iii. Development of rapport and trust continued with playing toys and reading children story books at the toy corner in the therapy room. His conversation showed some improvement after the third session. We started to focus on his positive aspects such as his look, his hobbies and his improved communication skills as well as confidence in expressing his ideas during play therapy and book reading. It is important to mention here that there was a time that he requested the therapist to accompany him for a medical assessment involving an $\mathrm{x}$-ray procedure at a government hospital. Taking into consideration of his psychological and cognitive conditions (low self-esteem and other borderline disorders) and also to maintain the rapport and trust that has been developed the therapist presented herself at the hospital for that procedure. Nevertheless at this juncture, there was still no mention about food and why he refused to eat. This was in agreement with Rogers (1957, reproduced in Kirschenbaum \& Henderson, 1990) who believed that "what clients need is not the judgment, interpretation, advice or direction of experts, but supportive counsellors and therapists to help them rediscover and trust their 'inner experiencing'..., achieve their own insights, and set their own direction" (Kirschenbaum, 2004, p. 121)

The therapist also guided him in writing short notes after each session. This was meant to give him some empowerment and showed that the therapist had trust in him writing his own report. As he did not read and write well, the therapist assisted him with the spellings. The report was brief and short and contained about four to five lines for each session. It was obvious that he got mixed up with the alphabets like ' $b$ ' with ' $d$ ', and ' $p$ ' with ' $q$ ' in his spellings. This is an indication of dyslexia - not being able to tell the difference between letters that have similar shape but different orientation.

\section{Behavioural Therapy}

After initial treatment sessions to establish a relationship with Arief, behavioural therapy techniques followed. In behavioural therapy, the goal is to reinforce desirable behaviours and eliminate unwanted or maladaptive ones. The techniques used 
in this type of treatment are based on the Behavioural theories ie. classical and operant conditionings (Cherry, 2012). The goal is to teach Arief new behaviours in that it minimize or eliminate the issue he was having.

\section{Intervention Strategies}

Arief had a propensity to lose his focus easily. He also could not sit still and at times just refused to participate in therapy activity. So operant conditioning was adopted in which behaviour modification was exercised by utilizing reinforcement to encourage or discourage certain behaviour. In this regard, rewards were set up. Arief was rewarded for engaging in positive behaviour. The reward was variety of stickers that boys might like such as pictures of transport, dinosaurs, children heroes (e. g. superman) etc.

i. We agreed that Arief would be rewarded for his good work and behaviour during the session which comprised of:

- giving eye contact when talking - one sticker of the therapist choice;

- less body movements while communicating (restlessness) - one sticker of the therapist choice;

- participating in conversation and activities - one sticker of the therapist choice; and

- writing notes in his diary - one sticker of his choice.

ii. Arief was assigned to write notes of his sessions with the therapist. He was also given a task to write his diary of activities in a notebook at home in between the sessions.

Sometimes he could get up to four stickers pasted on his note book. He gave the impression that he was happy and expressed that he liked to come to therapy sessions and looking forward to come again. Behaviour wise, Arief demonstrated some progress. His responses to questions got better. Apart from that, he was not only writing his activities at home with help of his mother, but he also read the report to the therapist. The report was brief but he has made some efforts. Further reward system will be presented in later sessions.

\section{Phase 2: Cognitive Behavioural Therapy (CBT)}

Once trust was developed and the client felt more comfortable in his interaction with the therapist and he demonstrated behaviour improvement, the therapy was focused on his irrational beliefs and maladaptive thoughts. The therapist asked him if he wanted to eat and he said, "Yes but I'm afraid that I'll get chocked" (Ya tapi takut tercekik). When asked what make him refused to eat, he gave similar reason, "I want to eat, but I am afraid that I might get choked" (Arief nak makan tapi kalau makan nanti tercekik). So, it was very obvious that he has irrational belief that he would get chocked if he consumed food.

\section{Intervention Strategies}

For the second phase of treatment, CBT approach was employed. CBT is a psychotherapeutic approach that addresses dysfunctional emotions, maladaptive behaviours and cognitive processes and contents through a number of goal-oriented, explicit systematic procedures. So, the name refers to behaviour therapy, cognitive therapy, and therapy based upon a combination of basic behavioural and cognitive principles and research (Schacter, Gilbert, \& Wegner, 2010). CBT refers to a group of approaches (i. e. rational emotive therapy, cognitive therapy) that presume a client's cognitions shape the way they feel and act (Guterman \& Rudes, 2005). "CBT works by changing people's attitudes and their behaviour by focusing on the thoughts, images, beliefs and attitudes that we hold (our cognitive processes) and how this relates to the way we behave, as a way of dealing with emotional problems" (Martin, 2003, p. 1). Hence, in utilizing CBT approach the 
researcher focused on how irrational beliefs or maladaptive thoughts contributed to the client's maladaptive emotions and behaviours.

The therapy aims to break overwhelming problems down into smaller parts to make them easier to cope with. During the treatment the therapist and client focus on the here and now. In other words, therapy focus on the then current issues and dilemmas while noting how past events has shaped his thinking and eventually his behaviours. The therapy was divided into two parts which were cognitive and behavioural phases respectively. In a simpler description, CBT is an actiondirective, solution-focused approach to therapy. By utilizing the therapeutic approach, the researcher helped the clients eradicate irrational briefs and move towards their goals in more effective and efficient manner as outlined by Guterman and Rudes (2005, pp. 230-239): (a) problem definition and goal setting; (b) accessing and examining thoughts, identifying irrational beliefs; (c) disputing irrational beliefs and other cognitive-behavioural techniques; (d) assigning homework and tasks; and (e) re-evaluating the problem and goal. In cognitive phase, the therapist focused on steps (a), (b) and part of (c) while in the behavioural phase, the therapist continued with another aspect of part (c) and proceed with (d) and (e).

\section{i. Cognitive Phase}

Cognitive processes refer to client's thoughts, including his ideas, beliefs and attitudes. The cognitive element of CBT looks at the way one's thoughts can trigger or stimulate certain feelings and behaviours. Its goal is to change patterns of thinking or behaviour that are behind people's difficulties, and so change the way they feel (Martin, 2013).

\section{(a) Problem Definition and Goal Setting}

Arief could not relate much about what brought him to the therapist except "My mother and father brought me here so that you can make me eat". However when asked whether he wanted to eat, he said, "Yes, I want to eat, but I am afraid if I get choked". This is the automatic thoughts that he had. Thus at this juncture, the goal of the therapy was also to help Arief understood negative thought patterns he might have, how they affected him and, more importantly, what he could do to change them. Once accomplished, he would subsequently be able to eat.

\section{(b) Accessing and Examining Thoughts, Identifying Irrational Beliefs}

From the therapist observation, Arief was scared to eat as he had developed the thought that the food would clog in his throat, remained there and subsequently he will be chocked. With reference to information obtained from his parents, his fearful and traumatic experience probably developed in his infancy i. e. when tube was inserted into his throat to such out phlegm was not attended to. Persuasion, pressure and force to eat did not seem to work. Although the incident took place when he was still very young to remember, most likely less attention was given on the psychological aspects which contribute to the underlying issues related to the problem especially his anxiety and fear. As suggested by Beck, these thinking patterns are building up in childhood, and become automatic and relatively fixed (Martin, 2013). So, he grew up believing that he could not eat and could never be able to eat. He was afraid to make any attempt to put food into his mouth. Attempts to feed him were unsuccessful as he got angry, threw tantrums and in due course totally rejected food. He only tolerated liquid as to him, "I drink water only because I won't get choked" (Arief minum air aje sebab tak tercekik).

\section{(c) Disputing Irrational Beliefs and Other Cognitive-Behavioural Techniques}

As treatment progressed, disputing irrational beliefs were initiated and cognitive restructuring techniques which aimed at recognizing and changing problem thinking patterns were introduced. An array of techniques was applied in CBT "to help individuals dispute irrational beliefs, and, in turn, eradicate emotional and behavioural problems so that they can work towards their goals in an effective and efficient manner" (Guterman \& Rudes, 2005, p. 226). 
Automatic thoughts and beliefs that perpetuate the problems ("I will get choked if I eat") are identified and work aimed at developing new perspectives and ideas began. The therapist only focused on two questions related to eating behaviour of people around him: "Have you observed people eating?" and "What happen to them when they eat?" Examples of his responses were as follows:

"My younger brother can eat and he doesn't have any problem"

"My classmates also eat and they are O. K."

"My friends who play football with me are strong and they play longer. They have energy and fit. . . because they eat"

'My classmates don't bring feeding bottles to school. ... teacher give food and they eat"

Next the therapist helped Arief to read a book entitled "Our Body" (Badan Kita). This was children book which displayed pictures of human body and explains the functions of parts of the body. There was a chapter on why people need food and what happen to them if they eat. Pictures of foods and food pyramid were also provided. There were also explanations on why people need food and the nutrition benefits of the food in the pyramid. He was later asked to explain the consequences if people do not eat. This required Arief to take the role of the person in the book where he has to post the questions to himself and then answer the questions:

"Why I need food?"

- Response: I need food because......"

"What will happen to me if I eat?

- Response: "If I eat. ......"

"What will happen to me if I do not eat?"

- Response: "If I don't eat ........."

*Answers were all based on the book that he had just read.

Later the therapist focused on the pictures of digestive system and showed to him that there is no obstruction in the throat that could block the movement of food when we swallow that could lead to choking. Arief was later shown a video on you tube entitled "Human Digestive System" (https: // www. youtube. com/watch?v=b20VRR9C37Q). This video began with the process of eating, i. e. putting food into mouth, biting, chewing and swallowing before the food enters the digestive system. After further explanation by the therapist Arief agreed that there is no obstruction in the throat that could block the movement of food that he would swallow that could lead to choking. This discussion was meant to dispute his irrational belief and restructure his automatic thought about "I will get choked if I eat."

His medical reports and the therapist opportunity to observe the X-ray procedure when the water that he swallowed flowed down straight into his stomach increase the confidence. At this juncture, the therapist believed that Arief was able to eat. The next question was posted, "Can we get something so that you can try to eat?" With a low voice he said "May be..... . but are you sure that I won't get choked?"

\section{ii. Behavioural Phase}

This is a continuation of the aforementioned step which was disputing irrational beliefs and other cognitive-behavioural techniques. Behavioural therapy notes that behaviour is often learned and can therefore be unlearned. It looks at unsafe or maladaptive behaviours and helps client to understand why the behaviour occur and what he can do to change them (Martin, 2013). Arief agreed that he could try to eat. These sessions started in the beginning of the third year of therapy. 
The therapist requested for Arief to come every week (Thursday) just to keep him in the right momentum as longer break period might affect his efficacy and motivation.

The following are the observations on the experience of Arief's break-through to eating which was done through a lot of persuasions:

\section{First week}

Arief was accompanied by his father. The therapist obtained consensus from him to begin feeding Arief with food. To begin with, the therapist used spoon to feed him strawberry flavoured blended ice. He showed grimaces like he was eating a bitter or sour food but swallowed the blended ice with much difficulty. The fear of swallowing was very obvious. He agreed on three spoons.

\section{Second week}

The therapist fed him with very soft vanilla flavoured puddings. His grimaces were quite bad this time and he was on the verge of throwing up - but did not vomit. He drank a lot of water after every feedings indicating that the fear of choking still existed. Arief looked very stressful and rejected the fifth spoon. So he was not force to take more puddings. The therapist noticed that he just swallowed and did not chew the food.

Reward system was again set-up here. He always asked the therapist if he could play computer games on her computer. The agreement was, he would be given five minutes of computer games for every spoon that he ate and it would begin in the coming session.

\section{Third week}

Deep breathing exercise was introduced to reduce his anxiety and stress. The therapist helped him to do jaw exercise involving jaw movements (open mouth widely and close, twisting to left and right and chewing exercise - without food). He was also taught to move his tongue from side to side to help him control food in the mouth when he began to consume solid food.

For eating session, there was not much of a difference - he took four spoons of chocolate flavoured very soft puddings. He still had a glass of plain water in his hand and quickly drank after every feeding. So as a reward he wall allowed to play computer game for 20 minutes after the session.

He was encouraged not to show grimaces and his facial reaction after each feeding improved. Arief's mother who accompanied him this time was asked to bring very soft rice porridge for the coming session. More importantly, Arief agreed to try.

\section{Fourth week}

This session began with breathing exercise followed by chewing and tongue movement exercises. Arief had never chewed anything before and hence he did not have the skill. Chewing and controlling food in his mouth could be quite challenging for him. This was very important as the therapist needed to prepare him for solid food. The concern was, he might get chocked if he simply swallowed the food and to redevelop his confidence could be more challenging.

The porridge looked almost like puree. It was rather tough to convince him that he would be alright if he eats. He was ready with two bottles of plain water this time. Arief tried to delay the feeding by asking the therapist a lot of questions - about the weather (it was raining heavily outside at that time) and about her students that he knew. He also made a lot of excuses by going to toilet, checking on who was walking outside the therapist office and sometimes pretended to look for his mother. He even hid under a table when the therapist answered a friend call at her office door. 
The therapist reminded him of what have been agreed in the previous session that he would eat and would be rewarded according to the number of spoons he took. After much persuasion and much difficulty, the therapist managed to feed him five spoons of porridge. He was on the brink of throwing up but managed to control.

Arief was encouraged to continue eating at home. When asked to suggest a person whom he preferred to feed him, he named the family maid, Bibik Ema. The therapist made a call to his maid and informed her about Arief's suggestion and made him talk about the request by himself. He was also asked to write about this in his session report. This is a kind of collaboration contract between the three of us - the therapist, the client and the care provider. He was rewarded with 25 minutes of computer games after the session.

\section{Fifth and Sixth Weeks}

Sessions in fifth and sixth weeks respectively still focused on his eating. The quantity of porridge had increased and at times the therapist managed to feed him up to 10 spoons. He still refused to chew and continued drinking water immediately after every spoon but with less quantity. Another significant observation was Arief could not identify taste differences. Drinks and food were always 'delicious' (sedap) to him. There was as time when I asked him about the taste of plain porridge, his response was 'salty' (masin). His mother conveyed to the therapist that when his grandfather who came home from a vacation asked him to taste salt from the Dead Sea, he replied that the taste was 'delicious' (sedap).

The therapist also helped him to hold his own spoon and put food into his mouth. This action was to develop independency and give him some empowerment and sense of responsibility. To reinforce his behaviour, the reward was not only on computer game but also ice-cream treats and buying book at the shops in the university compound. This reinforcement will be presented later in the psycho-educational approach.

\section{(d) Assigning Homework and Tasks}

Giving homework and tasks assignments between sessions are vital parts of the therapy process. What this might involve varied. In working with Arief, as mentioned earlier, at the start of the therapy, the therapist asked him to keep a diary of what he did between the sessions. He was not asked to write about his anxiety or incidents that provoke feelings of anxiety or fear toward certain things as he was not able to communicate much and express his feelings and emotion in the initial sessions. He usually wrote about things that he enjoyed doing such as an outing with his family. But when he came back, for the next session we discussed about his feeling and his answer was always "enjoyable" (seronok).

As the therapy progressed to another phase, the assignment given consisted of exercises to cope with problem situations of a particular kind. Arief was asked to write on what he had done and experience in the therapy session. At this stage, he was encouraged to write his feelings, emotion and wishes in the report. He also mentioned about his aspirations in education and career. As we proceeded into the third year, Arief was able to spell many words correctly, read his own report of activities at home faster and wrote better. Capital letters and small letters were still mixed-up. He also reported about the amount of food he consumed at home.

Several assignments were given to Arief. The first was to continue with jaw and chewing exercise. His mother was asked to help him with the chewing skill with an aid of a baby teether. The second was to encourage him to have hobbies which outcome could be used to make inferences to his problems related to eating. The first assignment was to rear fish, which the parents agreed to buy a small aquarium and a few pairs of gold fish. He was given the responsibility to feed the fish every morning before going to and coming home from school. Like fish which need to be fed to live, we also discussed why he also needed to eat his breakfast before he left home and eat again for lunch when he reached home. This developed a consciousness in him on why he need food and must eat every day.

Secondly, the therapist suggested to his mother to prepare several flower pots and encourage him to plant tree that could produce flowers or fruits in a short duration. He should also be given the responsibility to take care of the tree, including watering and fertilizing it. These assignments were aimed to help him develop awareness that fish and trees need food to live and survive. Subsequently, he was also made to understand why human being must consume enough food and good nutrition is important for their bodies. In the same way, Arief also need to eat good food to make him strong and healthy. 
At this point, the CBT approach seemed to work quite well to dispute and restructure his negative thoughts about food and eating and the cognitive-behavioural techniques planned for him managed to accomplish an important desired goal of the psychotherapy which was helping him to eat.

\section{(e) Re-evaluating the Problem and Goal}

In CBT approach, therapy goals and strategies have to be continually monitored and evaluated. Thus it is important to note that the goal of therapy is to dispute his irrational beliefs, restructure his distorted thoughts and eventually teach him new skills to more effectively manage his difficulties. Apart from that, he should be able to try to practice these skills outside the session and in his day-to-day life.

As Arief studied in a special educational need class, his mother reported that the lessons taught were more on the basic skills in reading, writing and arithmetic some drawing as well as handicraft activities. Thus, as extensively explained above, the homework and tasks given were practical, and involved trying out new behaviours, thinking strategies, etc. , rather than the kind of homework associated with his classroom learning.

There are no tests in CBT. Thus, tasks and activities that happened outside of sessions aimed to attribute improvement in his problems to his own efforts, in collaboration with the therapist and his family, especially his parents. Weekly reports from his parents were also utilized for the revaluation of the problem and therapy goals.

It is important to note that Arief showed better participation in the therapy. By the third year, he was able to follow instruction, participated in therapy activities, and showed better eye contact when communicating with the therapist. His communication has also improved and could express his feelings and thoughts.

\section{iii. Psychoeducational Approach}

"Psychoeducation is a professionally delivered treatment modality that integrates and synergizes psychotherapeutic and educational interventions" (Lukens \& McFarlane, 2004, p. 206). They indicated that in many instances, the client and/or family are considered partners with the treatment provider on the basis that the more knowledgeable the care recipients and informal caregivers are, the more positive health-related outcomes will be for all. Hence, psycho education can be observed as a more holistic and competence-based approach, emphasizing health, collaboration, coping, and empowerment (Dixon, 1999; Marsh, 1992 in Lukens \& McFarlane, 2004).

In working with Arief, the therapist believed that rather than focussing on working with him alone, the best possible results could be also realized when the psychoeducational intervention was initiated. The intervention was based on a collaborative partnership between the therapist, family and client. In this regard, as the therapy session progress, apart from direct therapist-client kind of relationship or rather expert-driven approach, we should also have indirect working relationship where family work together to come up with strategies for feeding the child takes charge of the child's development at home.

\section{Family Involvement}

Family members often experience heightened level of worry when they have someone among them who refused to eat. Parents often feel vulnerable in their efforts to treat a child who totally reject food. However, family involvement is critical as they are an integral part of the treatment team. The chances that our children recover from an eating disorder will be increased with family involvement in supporting and maintaining coping strategies (Ekern, 2012).

In Arief's case, his parents' strong support and help provided positive impact in the treatment. He was accompanied by either parents, or sometimes both of them came together. They left Arief alone with me and joined us at the end of the session to discuss about their son's progress and also to receive further assignments from the therapist to work with Arief 
at home. We planned on our roles and responsibilities - the therapist conducting the therapy and the parents providing support at home.

Family participation has also been demonstrated as effective method of treatment for many children with eating disorder (Robin, Gilroy \& Dennis in Vaughan, 2000). As Arief preferred to be fed by his family maid, the parents needed to make sure he ate the three main meals - breakfast, lunch and dinner and also reduce the quantity of water between each spoon.

The therapy also requires family working together to come up with strategies for feeding the child. Other than fish rearing and little agricultural activities, Arief's parents and the therapist also plan for other intervention strategies outside the session including improving his academic achievement and at the same time enhancing his self-esteem as well as psychosocial skills. Besides that, his other interest and strength were also explored. His parents sent him to tuition class and music lesson. A retired music director who came to know about our treatment strategies and his interest in music offered to give him free piano lessons.

Since Arief was in a special need class, he was given the privilege of staying longer in primary school. His parents made a request to the school to allow him to take the national assessment test for primary school which was compulsory for normal students. His examination result would determine if he qualified to study in regular classrooms under the Malaysia Ministry Education's inclusive education.

\section{Limitation of the Study}

Arief's treatment took almost three years. It is a rather long series of therapy. Sometimes the therapist could not see him for almost two months due to several reasons. Sometimes the parents could not take him for therapy sessions as his mother was busy with her food catering business and his mother was busy with his work commitment. The therapist also change her workplaces twice in the three years. Apart from that, Arief's case was the first child eating disorder problem handled by the therapist. A lot of research work and references had to be made to really understand the nature of the problem and to work on the right and feasible treatment plan, especially involving a child with borderline autism, dyslexia and ADHD.

\section{Recommendations for Further Study}

"Feeding problems, including those exhibited by children who have established patterns of eating, are not homogenous. Thus, treatment strategies should be selected individually based on existing eating patterns and potential maintaining variables" (Bachmeyer, 2009, p. 50). It is interesting to note that the treatment process of a child with complete food rejection problem is even more difficult but therapists and other professionals must trust that it is possible. The affected children might come from diverse family background along with different kinds of health problems. Eating problems themselves are complicated. Thus, additional research for prevention measures and treatment intervention must be carried out as a treatment strategy designed for one child probably might not work on other child or in other words it cannot be replicated for another child. Apart from that, parents' or other adults' in the family attention is also need to maintain appropriate mealtime behaviour.

\section{Summary and Conclusion}

The therapist believed that the treatment was successful. The goal of therapy which was to help him to eat was achieved. The intervention was carefully planned and carried out as this was the first experience of this therapist handling this type of eating disorder specifically total food rejection. What made it more challenging was that he has borderline dyslexia and autism and ADHD. To gain his focus, attention, and participation was sometimes tough and required a rather high level of patience and passion. 
Nevertheless, there were several factors that contribute to success of the therapy. Firstly, it was Arief trust on the therapist and also the unconditional positive acceptance on the therapist side. Once strong trust had been developed, his resistance towards the therapy activities was minimized. He was always looking forward to come to the therapy sessions. The pre and post intervention strategies for each session required careful preparation and lots of readings as this was the first time that the therapist was encountered with the problem in her years of practice. Furthermore, there is so little written on the topic of childhood food phobias and what more complete food rejection. Most literature groups it together with difficulty swallowing. However, application of CBT approach in the therapy appeared fruitful. In understanding the development of Arief's problem and the progress of his treatment, we might need to agree with Albert Ellis postulation in his $A B C$ model that "...people experience undesirable activating events $(A)$ about which they have rational and irrational beliefs $(B)$ which lead to emotional, behavioural, and cognitive consequences $(C)$. Rational beliefs lead to functional consequences, while irrational beliefs lead to dysfunctional consequences" (David, Szentagotai, Eva, \& Macavei (2005), p. 176). This opinion was really helpful in designing the intervention strategies.

Arief had to wait too long before he could consume solid food. Paediatricians and nutritionist believed that babies who are not introduced to solid foods until later in the first year may have a difficult time learning to eat different textures and flavours of foods. This was what exactly happened to Arief. Nonetheless for Arief's case, his parents believed that it was better late than never. Their tireless effort, support and cooperation facilitated the treatment procedure and process and eventually made a breakthrough to the treatment. The therapist terminated the session when Arief started to eat and had shown psychosocial improvement but Arief and his mother always report his progress through phone calls. He was still lacking in chewing skill. To develop skills and confidence for him to take solid food like rice, vegetable, fruit and other food associated with the Malay culture, and also eradicate the food phobia will require another long journey. Nonetheless, it is a pleasure to receive report from his parent that he had neither have serious health problems nor he had been admitted to hospital after the therapy termination, and more importantly, once he started to eat.

\section{References}

[1] American Psychiatric Association. (2000). Diagnostic and statistical manual of mental disorders (4th ed. , text rev. ). Washington, DC: Author

[2] Bachmeyer, M. H. (2010). An evaluation of motivating operations in the treatment of food refusal. PhD (Doctor of Philosophy) thesis, University of lowa. Retrieved March 3, 2014. http: //ir. uiowa. edu/etd/637

[3] Bachmeyer, M. H. (2009). Treatment of Selective and Inadequate Food Intake in Children: A review and practical guide. Behavior Analysis in Practice, Spring, 2 (1): 43-50 Retrieved June 22, 2014. http: //www. ncbi. nlm. nih. gov/pmc/articles/PMC2854063/

[4] Chatoor, I. , \& Ganiban, J. (2003). Food refusal by infants and young children: Diagnosis and treatment. Cognitive and Behavioral I Practice, 10 (2), 138-146.

[5] Cherry, K. (2012). Introduction to Operant Conditioning. Retrieved July 25, 2012. http: //psychology. about. com/od/behavioralpsychology/a/introopcond. htm

[6] Dahl, M. , Eklund, G. \& Sundelin, C. (1986). Early feeding problems in an affluent society. II. Determinants. Acta Paediatrica Scandinavica, 75, 380-7.

[7] David, D. , Szentagotai, A. , Eva, K. , \& Macavei, B. (2005). A synopsis of rational emotive

[8] behavior therapy (REBT): Fundamental and applied research. Journal of Rational-Emotive \& CognitiveBehavioral Therapy, 23, 175-221. Retrieved April 12, 2014. http: //dx. doi. org/10. 1007/s10942-005-0011-0,

[9] Douglas, J. (2002). Psychological treatment of food refusal in young children. Child and Adolescent Mental Health, 7, 173-180.

[10] Ekern, J. (2012). Teen, Adolescent and Children's Eating Disorders - Eating Disorder Hope. Retreived February 6, 2014. http: //www. eatingdisorder. hope. com/ 
[11] Field, D. , Garland, M. , \& Williams, K. (2003). Correlates of specific childhood feeding problems. Journal of Pediatrics and Child Health, 39 (4), 299-304.

[12] Gardner \& Shaw (2008). Behavioral problems of infancy and preschool children (0-5). Rutter's Child and Adolescent Psychiatry, 5th edition. Edited by M. Rutter, D. Bishop, D. Pine, S. Scott, J. Stevenson, E. Taylor and A. Thapar. UK: Blackwell Publishing

[13] Grohol, J. (2013). DSM-5 Changes: Feeding \& Eating Disorders. Psych Central. Retrieved December 3, 2013. http: //pro. psychcentral. com/2013/dsm-5-changes-feeding-eating-disorders/004412. html

[14] Guterman, J. , \& Rudes, J. (2005). A solution-focused approach to rational-emotive behavior therapy: Toward a theoretical integration. [Electronic version]. Journal of Rational \&Cognitive-Behavioral Therapy 23 (3), 223-244. Retrieved January 16, 2007, fromProQuest database

[15] Hay P. P, Bacaltchuk J, Stefano S, Kashyap P. (2009). Psychological treatments for bulimia

[16] nervosa and binging. Cochrane Database of Systematic Reviews: 2009: 4 CD000562 [PubMed]

[17] Kerwin, M. L. E. (1999). Empirically supported treatments in pediatric psychology: Severe feeding problems. Journal of Pediatric l Psychology 24 (3). 193-214.

[18] Kirschenbaum, H. \& Henderson, V. L. (Eds) (1990). The Carl Rogers Reader. London: Constable.

[19] Landreth, G. L. , \& Bratton, S. (2000). Play therapy. Journal of Counseling and Human Development, 31 (1), 112.

[20] Lukens, E. P. , McFarlane, W. R. (2004). Psychoeducation as Evidence-Based Practice: Considerations for Practice, Research, and Policy in "Brief Treatment and Crisis Intervention" Vol. 4 No. 3, a Oxford University Press 2004

[21] Martin, B. (2007). In-Depth: Cognitive Behavioral Therapy. Psych Central. Retrieved

[22] November 23, 2014. http: //psychcentral. com/lib/in-depth-cognitive-behavioral-therapy/000907

[23] Murphy, R, Straebler, S, Cooper, Z \& Fairburn, C. G. (2010). Cognitive Behavioral Therapy for Eating Disorders. Psychiatr Clin North Am. Sep 2010; 33 (3): 611-627. doi: 10. 1016/j. psc. 2010. 04.004

[24] Rodriguez, K.. (n. d. ). Applying an Integrated Approach to a Case Example: Cognitive Behavioral Therapy and Person-Centered Therapy. Retrieved July 4, 2012. https: //www. academia. edu/443748/

[25] Schacter, D. L. , Daniel T. Gilbert, D. T. ,Daniel M. Wegner, D. M. (2010). Psychology. Macmillan: Worth Publisher

[26] Staiano, A. (2003). Food Refusal in Toddlers With Chronic Diseases. Journal of Pediatric Gastroenterology \& Nutrition, 37 (3), 225-227. Retrieved May 2, 2012.

[27] http: //journals. Iww. com/jpgn/Fulltext/2003/09000/Food Refusal In Toddlers With Chronic Diseases. 4. $\underline{\text { aspx }}$

[28] Vaughan, 2000). Effective Treatments for Anorexia and Food Refusal in Children

[29] J Am Acad Child Adolesc Psychiatry. 1992 Sep;31 (5): 847-52. Retrieved Mac 21, 2013 http: //www. vanderbilt. edu/AnS/psychology/health_psychology/FoodRefusal. htm

[30] Zimmerman, B. (2010). Food Refusal. Retreive April, 23, 2013. foodrefusal. com 